\title{
Solar Energy Potential Estimation in Perak Using Clearness Index and Artificial Neural Network
}

\author{
Morteza Khalaji Assadi a1, Abdul Faliq Qushairi Bin Abdul Razak¹, Khairul Habib \\ ${ }^{1}$ Mechanical Engineering Department, Universiti Teknologi PETRONAS ,Bandar Seri \\ Iskandar, 31750 Tronoh, Perak, Malaysia
}

\begin{abstract}
In this paper solar energy potential has been estimated by two methods which are clearness index and artificial network (ANN) methods. The selected region is Seri Iskandar, Perak ( $4^{\circ} 24^{\prime}$ latitude, $100^{\circ} 58^{\prime} \mathrm{E}$ longitude, $24 \mathrm{~m}$ altitude). Experimental data (monthly average daily radiation on horizontal surface) was obtained from UTP solar research site in UTP campus. The data include the period of 2010 to 2012 and were used for testing the artificial neural network model and also for determination of clearness index. Also the experimental data of the three meteorological, Ipoh, Bayan Lepas \& KLIA were used in calculating the clearness index and for training the neural network. Result shows that clearness index for Seri Iskandar is 0.52 , the highest radiation is on February $\left(20.45 \mathrm{MJ} / \mathrm{m}^{2} /\right.$ day), annual average is $18.25 \mathrm{MJ} / \mathrm{m}^{2} /$ day and clearness index is more accurate than ANN when there is limited data supply. In general, Perak states show strong potential for solar energy application.
\end{abstract}

\section{Introduction}

Solar energy is the energy radiated by the sun in the electromagnetic radiation form. The solar constant related to extraterrestrial solar energy which is above the atmosphere, according the World Radiation Center (WRC) has adopted a value of $1367 \mathrm{~W} / \mathrm{m}^{2}$, with an uncertainties of the order of $1 \%$.By the definition, the solar constant is the energy from the sun per unit time received on a unit area of surface perpendicular to the direction of propagation of the radiation at mean earth- sun distance outside the atmosphere. Solar radiation at normal incidence received at the surface of the earth is subject to variations due to change in the extraterrestrial radiation and the to two additional and more significant phenomena :(1) atmospheric scattering by air molecules, water, and dust and (2) atmospheric absorption by $\mathrm{O}_{3}, \mathrm{H}_{2} \mathrm{O}$, and $\mathrm{CO}_{2}[1]$.

The amount of solar radiation which reaches on the ground is different in any region. Malaysia receives vast amount of solar energy with yearly average value of 1470 to $1900 \mathrm{kWh} / \mathrm{m}^{2}$ for different

\footnotetext{
${ }^{a}$ Corresponding author :morteza.assadi@petronas.com.my
} 
regions, thus suitable for implementing solar energy for both solar thermal application and photovoltaic (PV) technologies [2].

There are solar radiations data recorded in almost every state in Malaysia but mostly involves one city per state. Some of these data is partly missing and the data is not accurate enough to represent the state due to huge areas (e.g. Perak). This is where the solar estimation is needed in order to provide much reliable data.

Many estimation techniques have been used to predict the global solar radiation. In Malaysia, estimation based on Angstrom-Prescott model had been done to estimate daily global solar radiation in Kuala Terengganu [3]. Besides, there is also work been done by estimating monthly mean daily global solar radiation in eight cities including Kuching, Kota Kinabalu, Kota Bharu, Senai, Bayan Lepas, Kuala Lumpur, Petaling Jaya and Bandar Baru Bangi [4]. In [5], the global solar energy is modeled using linear, nonlinear, fuzzy logic and artificial neural network (ANN).

Little work had been done on clearness index and ANN estimation techniques in Perak states. The only relevant studies made was by [6] in estimating global solar radiation using clearness index in Kuala Terengganu. The value of the clearness index was compared with the studies made in [4]. As for ANN technique, it has been claimed to be more popular recently and was superior when compares with linear, nonlinear and fuzzy logic estimation techniques $[5,7]$. Therefore, this study is made to estimate and compare the monthly mean daily global solar radiation using clearness index and ANN with other cities within Malaysia

Selection of sites made was based on the availability of solar radiation data on that site. By doing this, it is easier to validate the data estimated by comparing it with the measured data. In this case, sites chosen must have meteorological stations in it. For this purpose, UTP Solar Research Site in UTP campus with the geographical coordinates of $4^{\circ} 24^{\prime} \mathrm{N}$ latitude, $100^{\circ} 58^{\prime}$ E longitude and $24 \mathrm{~m}$ altitude, was chosen as the site to be tested. As an addition, data from Ipoh, KLIA and Bayan Lepas meteorological stations were chosen to serve as input parameters for the testing sample.

\section{Clearness Index Method}

The monthly mean daily clearness index was calculated by taking a ratio of monthly mean daily global solar radiation, $\mathrm{H}_{M}$ to the monthly extraterrestrial radiation, $\mathrm{H}_{\mathrm{o}}$ The $\mathrm{H}_{\mathrm{o}}$ was derived from the following equation [1].

$$
H o=24 / \pi 3600 G_{s c}(1+0.033 \cos 360 D / 365)\left(\cos \varphi \cos \delta \sin \omega_{s}+(2 \pi \omega s) / 360 \sin \varphi \sin \delta\right)
$$

Where, $\mathrm{G}_{\mathrm{sc}}, \mathrm{D}, \varphi, \delta$ and $\omega \mathrm{s}$ are solar constant $(1367 \mathrm{~W} / \mathrm{m} 2)$, number of the days of the year starting from first January, latitude of the site $\left(^{\circ}\right)$, solar declination $\left(^{\circ}\right)$ and sunrise hour angle for the given month respectively. The solar declination and the sunrise hour angle can be computed by two equations below respectively [1].

$$
\begin{gathered}
\delta=23.45 \sin [360(\mathrm{D}+284) / 365] \\
\omega \mathrm{s}=\cos -1(-\tan \delta \tan \varphi)
\end{gathered}
$$

In order to compute the clearness index, average reading of measured monthly mean daily global solar radiation, $\mathrm{H}_{\mathrm{M}}$ and average reading of monthly mean daily extraterrestrial radiation, $\mathrm{H}_{\mathrm{o}}$ for Ipoh, KLIA and Bayan Lepas from January 2010 to December 2012 were taken. From this, the clearness index in Seri Iskandar can be estimated by using data from Ipoh, KLIA and Bayan Lepas. This clearness index is then been multiplied with the calculated monthly average daily extraterrestrial radiation in Seri Iskandar, to yield the required data which is the monthly mean daily global radiation. 


\section{Artificial Neural Network method}

The data is simply divided into training set and testing set. The training set contains secondary data from Ipoh, KLIA and Bayan Lepas stations that consists of 9 parameters. These parameters is further specified into inputs and output where the latitude, longitude, month of the year, altitude, solar declination, sunrise hour angle, day length, monthly mean daily extraterrestrial radiation are inputs and monthly mean daily global radiation is the output. While the testing set consists data from UTP Solar Research Site with the same set parameters as well. The training set needs to be randomized and both the training and testing set are normalized into the value of -1 to 1 . Only then, the neural network is created.

The ANN technique employed the multi-layer feed forward neural network where it takes the training algorithm of Levenberg Marquardt (LM). It was claimed that it is the most accurate algorithm to be used and yields the best results compare to other algorithms $[9,10]$. The number of hidden layer is set to one in order to avoid complexity during the process. Moreover, performance function of Mean Square Error with regularization is used to avoid over fitting from occurring [11]. The activation function use in this process is based on 'tansig' equation as it is proven to be more accurate compare to other equation such as 'logsig' and 'purelin' [12]. The hidden neuron however is varied from 3 to 25 to provide wide range of results accuracy based on Root Mean Square Error (RMSE) obtained.

After several training, the network is saved, and the process continues with simulation of testing data. Results obtained will be in the form of -1 to 1 , therefore, it needs to be de-normalized so that comparison with measured data can be made. The process is continued till neurons of 25 .

\section{Statistical parameter (RMSE)}

Statistical parameter of RMSE is used to evaluate the accuracy of the data estimated from modeling techniques used with the measured data obtained from stations. The RMSE value closer to zero is preferable as it shows some accuracy in the techniques used. From this, validation of data can be done, thus making the estimation model valid to be use in case of unavailable data in the future.

$$
R M S E=\sqrt{\left[\frac{1}{n} \sum_{1}^{n}\left(H_{c}-H_{m}\right)^{2}\right]}
$$

Where, $\mathrm{H}_{\mathrm{C}}$ is monthly average daily global radiation calculated, $\mathrm{H}_{\mathrm{m}}$ is monthly average daily global radiation measured and $\mathrm{n}$ is the number of months.

\section{Results and Discussion}

Clearness index generated is compared with other cities within Malaysia that have high solar radiation comprises of Kuala Terengganu, Kuching, Kota Kinabalu and Kota Bharu as per shown in Table 1.

Based on the Table 1, the annual average of clearness index for Seri Iskandar is approximately 0.52 , making it comparable with other states that have greater clearness index such as Kuala Terengganu (0.53) and Kota Kinabalu (0.54). The clearness index pattern can be considered as stable throughout the year with the range varies from 0.47 to 0.57 . This is by 0.1 differences which are slightly low, thus more stable as compare to Kuala Terengganu with differences of 0.2 .

The high clearness index shows the existence of clear sky condition, thus the solar radiation tend to be high. This proves that Seri Iskandar area develops great potential of solar radiation. 
Table 1.Clearness Indexes of different Cities

\begin{tabular}{|c|c|c|c|c|c|}
\hline \multirow{2}{*}{ Months } & \multicolumn{5}{|c|}{ Clearness Index } \\
\cline { 2 - 6 } & Seri Iskandar & Kuala Terengganu & Kuching & Kota Kinabalu & Kota Bharu \\
\hline Jan & 0.51 & 0.54 & 0.35 & 0.55 & 0.51 \\
\hline Feb & 0.57 & 0.62 & 0.38 & 0.57 & 0.52 \\
\hline Mar & 0.52 & 0.57 & 0.41 & 0.56 & 0.53 \\
\hline Apr & 0.54 & 0.64 & 0.36 & 0.59 & 0.54 \\
\hline May & 0.52 & 0.54 & 0.37 & 0.53 & 0.48 \\
\hline Jun & 0.54 & 0.48 & 0.48 & 0.53 & 0.48 \\
\hline Jul & 0.53 & 0.53 & 0.45 & 0.51 & 0.45 \\
\hline Aug & 0.51 & 0.53 & 0.41 & 0.51 & 0.46 \\
\hline Sep & 0.50 & 0.53 & 0.43 & 0.50 & 0.50 \\
\hline Oct & 0.49 & 0.44 & 0.41 & 0.53 & 0.47 \\
\hline Nov & 0.49 & 0.49 & 0.41 & 0.53 & 0.39 \\
\hline Dec & 0.47 & 0.42 & 0.36 & 0.54 & 0.37 \\
\hline $\begin{array}{c}\text { Annual } \\
\text { Average }\end{array}$ & 0.52 & 0.53 & 0.40 & 0.54 & 0.47 \\
\hline
\end{tabular}

Table2 shows the comparison made between Seri Iskandar and other places within Malaysia that obtained from previous study. It is clearly shown that the highest solar radiation occurs on the month of February with the value was $20.45 \mathrm{MJ} / \mathrm{m}^{2} /$ day. This is in line with the results from Table I where the clearness index is highest on February as well the annual average of global solar radiation was $18.25 \mathrm{MJ} / \mathrm{m}^{2} /$ day. This is comparable with Kuala Terengganu and slightly lower from Kota Kinabalu with the differences around 1.0. It can also be seen that the solar radiation is gradually decreases starting October onwards. It is the period when the northeast monsoon occurs in which induces rainfall that could heavily affects the clearness index to be low, thus the global radiation is likely to be low as well.

Table 2.Global Solar Radiation of different Cities

\begin{tabular}{|c|c|c|c|c|c|}
\hline \multirow{2}{*}{ Months } & \multicolumn{5}{|c|}{ Clearness Index } \\
\cline { 2 - 6 } & Seri Iskandar & Kuala Terengganu & Kuching & Kota Kinabalu & Kota Bharu \\
\hline Jan & 17.18 & 17.91 & 12.02 & 17.71 & 16.26 \\
\hline Feb & 20.45 & 21.60 & 13.35 & 19.36 & 17.72 \\
\hline Mar & 19.29 & 21.40 & 15.39 & 20.97 & 19.72 \\
\hline Apr & 19.88 & 23.64 & 13.07 & 21.64 & 19.74 \\
\hline May & 18.54 & 20.34 & 13.42 & 20.16 & 18.23 \\
\hline Jun & 18.53 & 17.42 & 16.28 & 19.11 & 17.10 \\
\hline Jul & 18.42 & 19.43 & 16.57 & 19.41 & 17.17 \\
\hline Aug & 18.46 & 19.15 & 15.14 & 19.44 & 17.42 \\
\hline Sep & 18.32 & 20.20 & 15.79 & 18.20 & 18.12 \\
\hline Oct & 17.63 & 16.40 & 15.23 & 19.21 & 17.09 \\
\hline Nov & 16.82 & 16.24 & 14.92 & 18.08 & 13.28 \\
\hline Dec & 15.48 & 13.38 & 12.56 & 18.00 & 12.15 \\
\hline $\begin{array}{c}\text { Annual } \\
\text { Average }\end{array}$ & 18.25 & 18.92 & 14.48 & 19.27 & 17.00 \\
\hline
\end{tabular}


Fig. 1 shows the estimated solar radiation pattern for 2010, 2011 and 2012 for the 3 years period. It can be described that Seri Iskandar shows similar pattern of solar radiation for the 3 -years period. This means that the climate is stable over the course of the three years and is believed to be the same for the after years (2013 onwards). Therefore, in a long term, it is a good move to develop solar application based on the graph patterns. Beside the amount of solar radiation is pretty high especially from February to July. However, starting August of the year, the line pattern gradually drops till January next year. This is where the clearness index is low, in which making the solar radiation low as well.

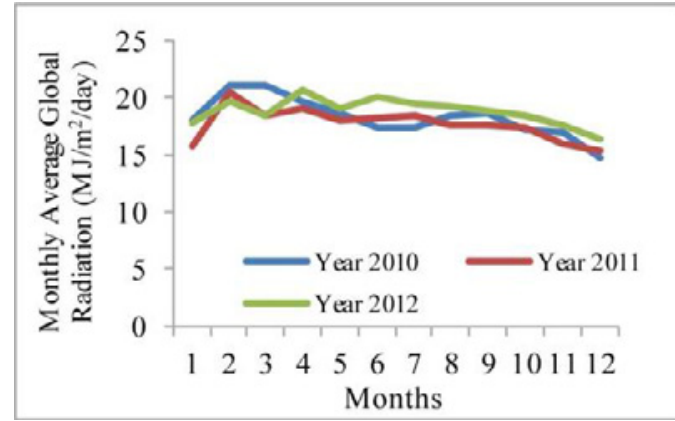

Fig.1 Solar radiation pattern in Serilskandar for 3 years period.

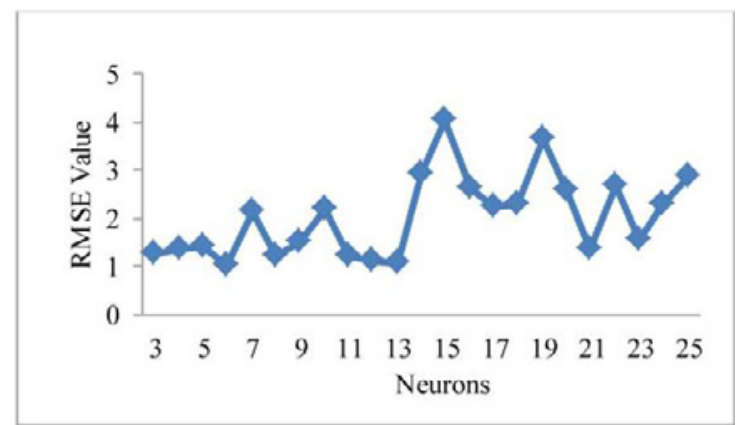

Fig.2 RMSE value of neurons 3 to 25

For ANN, the analysis can be made on the RMSE value with respect to the neurons setting from 3 to 25 as in Fig. 2. It is clearly seen that the RMSE value is in stable pattern from neurons 3 to 13 . For neurons above 13, the RMSE value tends to be unstable and differs greatly. Therefore, having said that to avoid complexity when use this model, it is safe to use neuron 3 to 13 . Besides, the lowest RMSE are achieved in this range when the neuron is set to 6 with the RMSE value of 1.02 .

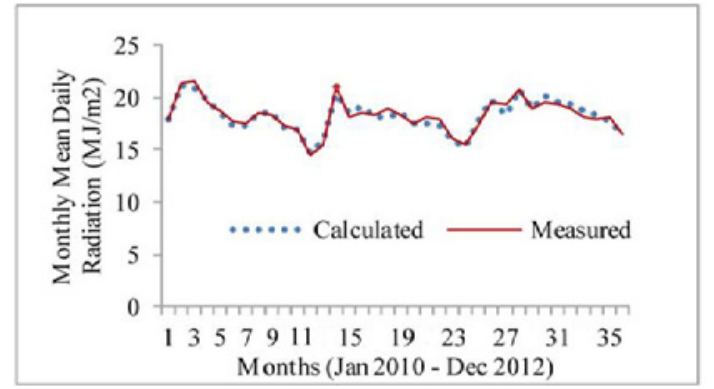

Fig. 3 Graph of calculated and measured value using clearness index

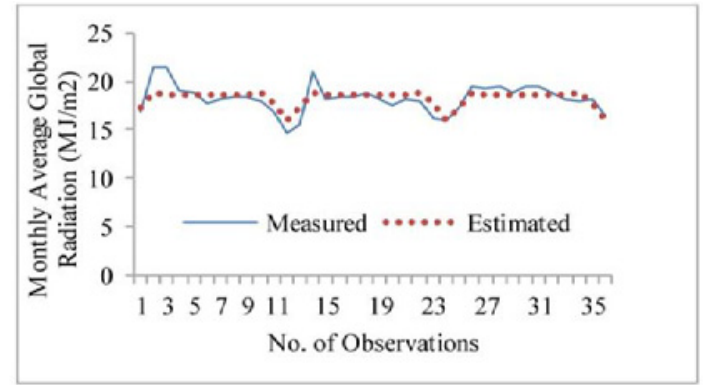

Fig.4 Graph of measured and estimatedvalue using ANN

Based on the observation in Fig. 3, the figure shows a good agreement between the measured data and calculated data. Using the statistical parameters such as RMSE, it is found that the error between the measurements and calculations is relatively low, with the value of 0.39 . This gives a good point that the estimation done earlier was made correctly as the objective of the validation here is to yield lowest possible value of RMSE. In this case, the RMSE value is acceptable (close to zero). Therefore, the clearness index model developed earlier can be used in Seri Iskandar .

Fig. 4 shows a comparison between the measured data with the estimated data. This is the pattern for the testing phase which has been simulated after several training of ANN using 3 years period. For improvement, long term data shall be supply for training purposes. This enable the network to yield better results, thus making the testing phase conducted easily. In this case, only 3 years data is available for study as there is no data recorded for the previous year (before 2010). 
For ANN, the RMSE value range from 1.02 to 4.00 for neurons 3 to 25 (Fig3). As been stated earlier to use neurons 3 to 13 due to their stability, this range of RMSE yields the maximum value to be 2.20 while the minimum value is still 1.02 when neuron is set to 6 . Hence, as the RMSE is lower, the estimation using ANN model can also be used to generate the required result which is solar radiation. In short, other than the clearness index which use mathematical equation, one can also estimate the solar radiation using simulation of ANN developed earlier for any area that do not have solar radiation data.

Between those estimation techniques which is clearness index and ANN, it is obvious that clearness index technique is more accurate compare to ANN as it yields the lowest RMSE value. This shows disagreement with previous studies that been done by [7] which states that ANN is the most superior compare to others. The probability of this disagreement might be due to the fact that the data supplied for ANN is limited in this study where only 3 years period were used. It is important to note that most ANN studies in Malaysia used long term data that accounts for 10 years and above including study made by [7]. Besides, the ANN is based on the flexibility, where in order to produce accurate results, more inputs must be provided so that the network can make better training process. Therefore, in case of short term supplied of data (in this case 3 years) or less number of observation, it is best to use clearness index method for predicting the solar energy. Otherwise, the ANN method shall be selected.

\section{Conclusion and Recommendation}

Monthly mean daily global solar radiation in Seri Iskandar had been studied using estimation techniques of clearness index and ANN. From the analysis that been done, following conclusions were drawn; Highest monthly mean global irradiation is on February of the year and the value was 20.45 $\mathrm{MJ} / \mathrm{m}^{2} /$ day. Annual average global radiation in Seri Iskandar was $18.25 \mathrm{MJ} / \mathrm{m}^{2} /$ day and average clearness index is found to be 0.52. This is comparable with other cities that have greater solar potential i.e. Kuala Terengganu with 0.53 and Kota Kinabalu 0.54. Best neurons to be use in ANN is from 3 to 13 from the range of 3 to 25 . This is due to their stability of graph pattern among each neuron when generating the required results. Lowest RMSE is 1.02 when neuron is set to 6. RMSE for clearness index and ANN is 0.39 and 1.02 respectively. Seri Iskandar shows similar pattern for over 3years period. This shows the stable climate at Seri Iskandar. The amount of solar radiation is high on February till July. Then, it will gradually decrease starting August till January next year. Clearness index is shown to be more accurate compare to the ANN in case of limited data provided (in this case 3 year's period).

For future works, the same studies shall also be done on the northern and southern region of Malaysia especially in the major cities in huge states. By doing this, comparison of clearness index can be made, thus increasing the market of solar energy industry as the data can be estimated without depending on measuring equipment. As for ANN, long term data of 10 years above shall be used in order to produce better result.

In a nutshell, this study achieved both of the objectives which are to estimate and compare the solar radiation using clearness index and ANN with other cities within Malaysia. Generally, Perak states is comparable with other states in Malaysia that is known already to have great solar intensity like Terengganu and Sabah. Therefore, Perak states or Seri Iskandar specifically, show a good prospect and have strong solar intensity for the applications of solar energy.

\section{Acknowledgement}

The authors would like to thank Universiti Teknologi PETRONAS for providing facilities and financial support. 


\section{References}

1. Duffie J.A. \& Beckman W.A., "Solar Engineering of Thermal Processes", John Wiley and Sons, New York, USA. (2006).

2. Mekhilef S., Safari A., Mustaffa, W. E. S., Saidur R., Omar R. \& Younis, "Solar energy in Malaysia: Current state and prospects." Renewable and Sustainable Energy Reviews, 16(1), pp. 386396, (2012).

3. Muzathik A.M., Nik W.B.W., Ibrahim M.Z., Samo K.B., Sopian K. \& Alghoul M.A., "Daily Global Solar Radiation Estimate Based on Sunshine Hours", International Journal of Mechanical and Materials Engineering, Vol. 6, pp. 75-80,( 2011).

4. Sopian, K. Othman, M.Y., "Estimation of monthly average daily global solar radiation in Malaysia", Renewable Energy, 2, 319-325, (1992).

5. Khatib T, Mohamed A, Mahmoud M. \& Sopian K., "Modeling of Daily Solar Energy on a Horizontal Surface for Five Main Sites in Malaysia”, International Journal of Green Energy, pp. 795$819,(2011)$.

6. Muzathik A.M., "Potential of Global Solar Radiation in Terengganu, Malaysia". International Journal of Energy Engineering, Vol. 3,pp.103-136, (2013).

7. Muzathik A.M., "Potential of Global Solar Radiation in Terengganu, Malaysia". International Journal of Energy Engineering, Vol. 3, pp. 130Khatib T, Mohamed A \& Sopian K., "A Review of Solar Energy Modeling Techniques", Renewable and Sustainable Energy Reviews, (2012).

8. Dhar V.K., Tickoo A.K., Koul R. \& Dubey B.P., "Comparative performance of some popular artificial neural network algorithms on benchmark and function approximation problems", Indian Academy of Sciences, Vol. 74, pp. 307-324, (2009).

9. Adamowski J. \& Karapataki C., "Comparison of Multivariate Regression and Artificial Neural Networks for Peak Urban Water-Demand Forecasting: Evaluation of different ANN learning algorithms", Journal of Hydrologic Engineering, pp. 729-743, (2010).

10. Sivamadhavi V. \& Selvaraj R.S., "Prediction of Monthly Mean Daily Global Solar Radiation using Artificial Neural Network", Journal Earth System Science, pp. 1501-1510, (2012).

11. Chayjan R.A. \& Esna-Ashari M., "Comparison between Artificial Neural Networks and Mathematical Models for Equilibrium Moisture Characteristics Estimation in Raisin", Agricultural Engineering International, Vol. 12, (2010). 